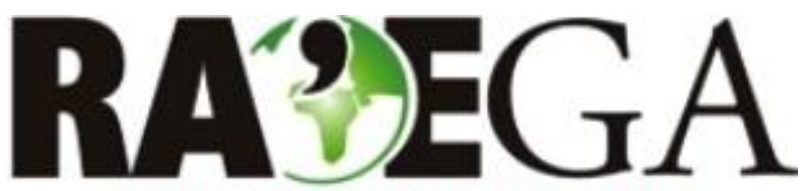

O ESPACO GEOGRÁFICO EM ANÁLISE

\title{
ANÁLISE DA FRAGMENTAÇÃO DA PAISAGEM DO PARQUE NACIONAL DA SERRA DA CANASTRA E DE SUA ZONA DE AMORTECIMENTO - MG
}

\section{ANALYSIS OF FRAGMENTED LANDSCAPE OF THE SERRA DA CANASTRA NATIONAL PARK AND ITS BUFFER ZONE - MG}

\author{
Amanda Alves dos Santos \\ Analista de meio ambiente do Instituto Terra Brasilis \\ Belo Horizonte, MG \\ e-mail: amandalves9@yahoo.com.br \\ Maria Márcia Magela Machado \\ Professora da Universidade Federal de Minas Gerais (UFMG) \\ Instituto de Geociências \\ Belo Horizonte, MG \\ e-mail:mmarciamm@gmail.com
}

\section{Recebido em: 28/04/2014}

Aceito em: 23/09/2014

\section{Resumo}

O Parque Nacional da Serra da Canastra (PNSC), localizado na porção sudoeste do estado de Minas Gerais é uma significativa Unidade de Conservação (UC) do Cerrado. Sua paisagem é composta de ambientes preservados e antropizados devido, principalmente, a problemas de regularização fundiária. Seu entorno vem sendo cada vez mais degradado pelos diferentes tipos de uso da terra, fragmentando a paisagem e aumentando a pressão antrópica sobre o PNSC. Neste contexto, o presente estudo teve como objetivo mapear o grau de fragmentação da cobertura vegetal do PNSC e de sua zona de amortecimento de forma a subsidiar o planejamento dessa paisagem. O mapeamento proposto foi fundamentado na abordagem conceitual metodológica da Ecologia de Paisagem e em técnicas de geoprocessamento. O mapa de cobertura vegetal e uso do solo na escala de 1:150.000, base para o mapeamento proposto, foi elaborado a partir de imagens Landsat 8 do ano de 2013. Para as classes de cobertura vegetal obtidas foram 


\section{ANÁLISE DA FRAGMENTAÇÃO DA PAISAGEM DO PARQUE NACIONAL DA SERRA DA CANASTRA E DE SUA ZONA DE AMORTECIMENTO - MG}

calculados métricas de paisagem que, conforme suas características ecológicas, tiveram seus valores reclassificados e integrados por meio de álgebra de mapas resultando no mapa síntese de grau de fragmentação. As manchas identificadas com baixo grau de fragmentação são majoritárias na área de estudo e estão espacialmente concentradas. Já os fragmentos com alto e médio grau de fragmentação correspondem a menores áreas e não apresentam padrão de distribuição espacial. Observou-se que o grau de fragmentação está mais relacionado com as formações geomorfológicas do que com a existência da UC.

Palavras-chave: Ecologia de Paisagem, Métricas de Paisagem, Geoprocessamento.

\section{Abstract}

The National Park of Serra da Canastra (PNSC), located in the southwestern portion of the state of Minas Gerais, is a significant Cerrado preservation unity. Its landscape, consists of preserved and anthropogenic environments, mainly due to problems of regularization, and its surroundings, are being increasingly degraded by different types of soil use, fragmenting the landscape, and increasing anthropogenic pressure on the PNSC. In this context, the study objective is to map the degree of fragmentation of the vegetation cover of the PNSC and its buffer zone, in order to support the planning of this landscape. The proposed mapping, was based on landscape ecology methodological conceptual approach and Geoprocessing techniques. The map of the vegetation cover and soil use in the scale of 1:150,000, the basis for the proposed mapping, was prepared from Landsat 8 images of the year 2013. For the vegetation cover classes obtained, landscape metrics were calculated, which according to their ecological characteristics, had their values reclassified and integrated through algebra maps, resulting in a "fragmentation degree synthesis map". The fragments identified with low degree of fragmentation, occupy a larger portion of the study area and are spatially concentrated. And the fragments with high and medium degree of fragmentation, correspond to smaller areas and have no spatial pattern distribution. It was observed that the degree of fragmentation is more related to the geomorphological formations, than to the existence of this preservation unity.

Keywords: Landscape Ecology, Landscape metrics, Geoprocessing.

\section{INTRODUÇÃO}

O Brasil é um dos países do mundo mais ricos em megadiversidade (MITTERMEIER, 2005). Entretanto, as crescentes ameaças aos recursos naturais existentes apontam para redução, cada vez maior, desse patrimônio. Essas ameaças podem ser encontradas em todos os biomas brasileiros e se expressam, 


\section{ANÁLISE DA FRAGMENTAÇÃO DA PAISAGEM DO PARQUE NACIONAL DA SERRA DA \\ CANASTRA E DE SUA ZONA DE AMORTECIMENTO - MG}

principalmente, por meio da fragmentação de hábitats ocasionada pela ocupação para produção agrícola, criação de gado, mineração e expansão urbana.

Como estratégia de preservação e/ou conservação dos recursos naturais remanescentes, os órgãos ambientais brasileiros tem criado unidades de conservação (UC's). Com esse procedimento tem-se que grande parte das UC's brasileiras já apresenta, desde a sua origem, conflitos territoriais de acesso aos recursos e de pressão antrópica interna e externa (CASTRO JUNIOR, 2009).

Essa realidade reforça a necessidade de ações voltadas para a conservação da biodiversidade que considerem o planejamento da paisagem da área protegida $e$ do seu contexto regional. A ausência de práticas nessa direção pode levar ao fracasso parcial ou total do objetivo de conservação proposto, uma vez que as UC's "precisam estar integradas a suas áreas periféricas para evitar seu isolamento genérico e fragmentação" (DIOS; MARÇAL, 2009).

O Parque Nacional da Serra da Canastra (PNSC) foi criado em 1972 contemplando uma área de aproximadamente 200.000 ha. Localiza-se na porção sudoeste do estado de Minas Gerais, no bioma Cerrado (Figura 1). Desde sua criação até a atualidade essa UC apresenta conflitos relacionados, principalmente, com a regularização fundiária das propriedades inseridas no limite definido pelo seu decreto de criação. Essa situação faz com que as pressões existentes no entorno da Unidade sejam estendidas para o seu interior intensificando os processos de degradação dessa paisagem.

Sua Zona de Amortecimento (ZA) ocupa, aproximadamente, 270.000 ha e apresenta, assim como o PNSC, alta diversidade biológica com ocorrência da espécie ameaçada de extinção Mergus Octosetaceus. A ZA é composta por ambientes com usos diversificados, destacando-se as atividades agropecuárias, as áreas com urbanização e os lagos artificiais do reservatório da Usina Hidrelétrica (UHE) de Furnas e da UHE Mascarenhas de Morais. 


\section{ANÁLISE DA FRAGMENTAÇ̃̃O DA PAISAGEM DO PARQUE NACIONAL DA SERRA DA CANASTRA E DE SUA ZONA DE AMORTECIMENTO - MG}

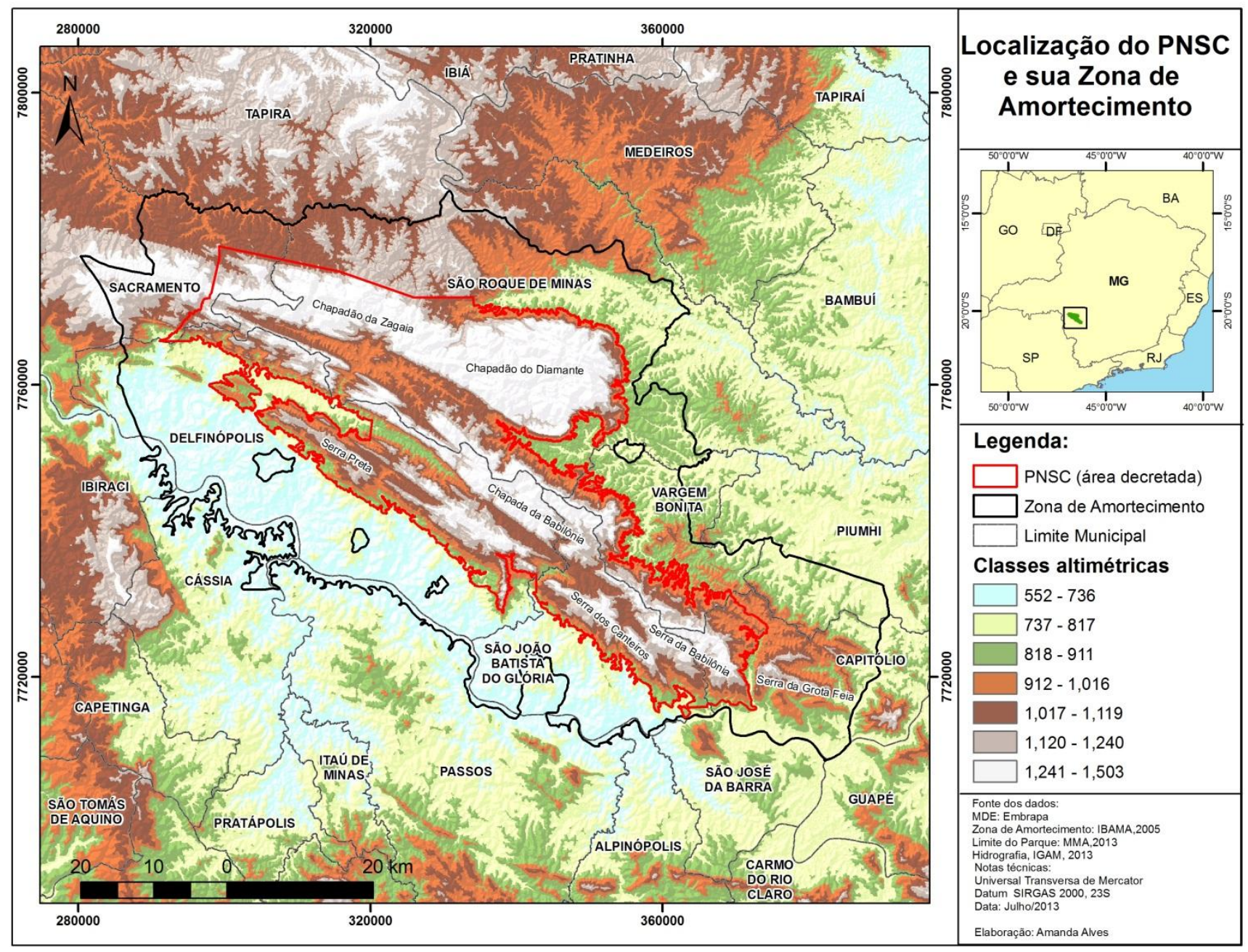

Figura 1: Mapa de Localização.

Os tipos de uso atuais e pretéritos existentes no PNSC e em sua ZA vêm descaracterizando essa paisagem, principalmente, pela substituição da cobertura vegetal por formas de uso antrópico caracterizando um cenário de fragmentação de hábitats. Considerando esse contexto, o objetivo desse artigo é mapear o grau de fragmentação da cobertura vegetal do Parque Nacional da Serra da Canastra e sua Zona de Amortecimento (MG) utilizando a abordagem conceitual metodológica da Ecologia de Paisagem e técnicas de geoprocessamento. Esta proposta constitui uma contribuição ao planejamento dessa paisagem visando garantir a manutenção de sua viabilidade ecológica. 


\section{ANÁLISE DA FRAGMENTAÇÃO DA PAISAGEM DO PARQUE NACIONAL DA SERRA DA \\ CANASTRA E DE SUA ZONA DE AMORTECIMENTO - MG}

\section{A ECOLOGIA DE PAISAGEM APLICADA AO ESTUDO DA FRAGMENTAÇÃO}

A Ecologia de Paisagem é uma ciência que vincula as disciplinas geografia e ecologia com o objetivo de entender como os processos ecológicos são influenciados pelos padrões espaciais da paisagem. Dramstad et. al (1996) aponta que por volta de 1950 já é possível encontrar estudos envolvendo a história natural com os padrões espaciais de grandes áreas, esses estudos, normalmente, eram realizados por geógrafos, pesquisadores de solo, climatologistas e pesquisadores de história natural. Para Soares-Filho (1998) essa ciência "combina a abordagem horizontal do geógrafo, através do exame das inter-relações espaciais de um fenômeno natural, com a abordagem vertical de um ecologista. Por isso, ela se desenvolveu a partir de uma interface comum as duas ciências, cujo tema central é conhecido como paisagem".

Um dos aspectos essenciais de estudo da paisagem sob o olhar dessa ciência é a estrutura. Ela é caracterizada como o arranjo ou padrão espacial produzido pelo relacionamento de suas unidades interativas, que podem ser: unidades de ecossistemas, de vegetação ou de uso e ocupação do solo (METZGER, 2009). Esse conceito advém do reconhecimento de que um arranjo espacial da paisagem, em um determinado tempo, pode revelar não só os processos que estão ocorrendo, mas também refletir os processos que determinaram 0 seu desenvolvimento.

A fragmentação é um dos processos que alteram a estrutura da paisagem. Por meio dele hábitats contínuos são substituídos por hábitats divididos em manchas mais ou menos isoladas resultando na "criação em larga escala, de habitats ruins, ou negativos, para um grande número de espécies" (RAMBALDI, 2003). Observa-se que nesse processo ocorre a reestruturação dos elementos que compõe a matriz da paisagem por meio da introdução de elementos antrópicos. Esses alteram os fragmentos interferindo em seu tamanho, forma e distância entre fragmentos de mesmo tipo. Tem-se então que o estudo dessas características das manchas proporciona considerável entendimento da fragmentação da paisagem. 


\section{ANÁLISE DA FRAGMENTAÇÃO DA PAISAGEM DO PARQUE NACIONAL DA SERRA DA CANASTRA E DE SUA ZONA DE AMORTECIMENTO - MG}

O tamanho é "a dimensão, a área de cada mancha e tem influência no nível de energia e nutrientes disponíveis e no número, tipo e fluxo de espécies" (CASIMIRO, 2002). De acordo com Forman e Godron (1986) manchas grandes são responsáveis pela manutenção da biodiversidade e de processos ecológicos de larga escala. Já os fragmentos menores, apesar da redução de sua função ecológica, funcionam como elementos de ligação, trampolins ecológicos (stepping stones) entre grandes áreas promovendo um aumento no nível de heterogeneidade da matriz e atuando como refúgio de espécies que requerem ambientes particulares que só ocorrem nessas áreas (FORMAN; GORDON, 1986).

A forma tem relação direta com a borda: quanto mais irregular a forma maior será a proporção de área de borda, a qual apresenta características próprias de grande diversidade e dinâmica, mas que se comportam de maneira diferente do que o seu interior (CASIMIRO, 2002). Potencialmente, as manchas mais regulares são naturais e as mais irregulares são antropizadas. Para o primeiro tipo há maior diversidade de espécies, menor número de barreiras em seu interior e maior eficácia na alimentação de suas espécies. Já para o segundo, há expressiva atuação do efeito de borda. Esse efeito pode ser definido como a modificação das características naturais que ocorrem na borda de dois ecossistemas adjacentes (MURCIA, 1995), promovendo modificações nas populações e nos processos ecológicos.

Já a distância entre fragmentos do mesmo tipo é uma aproximação da distância que as espécies devem percorrer para encontrar outros fragmentos que tenham condições ecológicas semelhantes à mancha de origem (LANG e BLASCHKE, 2006). Maiores distâncias entre as manchas indicam piores condições de hábitat e, consequentemente, uma paisagem mais fragmentada.

A variabilidade espacial dessas características dos fragmentos geralmente é restituída num mapa temático e por meio desse é possível quantificar, com métricas de paisagem, a sua estrutura. Essa quantificação proporciona a obtenção de índices relativos aos fragmentos, à classe e à paisagem que possibilitam a mensuração da 


\section{ANÁLISE DA FRAGMENTAÇÃO DA PAISAGEM DO PARQUE NACIONAL DA SERRA DA \\ CANASTRA E DE SUA ZONA DE AMORTECIMENTO - MG}

fragmentação da paisagem. Os índices de paisagem que foram empregados nesse trabalho são descritos a seguir:

\begin{tabular}{|c|c|c|c|c|}
\hline Métrica & Sigla & Equação & Descrição & Caracterização \\
\hline $\begin{array}{l}\text { Área dos } \\
\text { fragmentos }\end{array}$ & AREA & $A R E A=a_{i j}\left(\frac{1}{10.000}\right)$ & $\begin{array}{l}a_{i j}=\text { área }\left(\mathrm{m}^{2}\right) \text { de } \\
\text { cada fragmento } i j x\end{array}$ & $\begin{array}{l}\text { Área de cada fragmento } \\
\text { (ha). }\end{array}$ \\
\hline $\begin{array}{l}\text { Área núcleo } \\
\text { dos } \\
\text { fragmentos }\end{array}$ & CORE & CORE $=a_{i j}^{c}\left(\frac{1}{10.000}\right)$ & $\begin{array}{lr}\boldsymbol{a}_{i f}^{e}=\text { Área } & \text { núcleo } \\
\left(\mathrm{m}^{2}\right) \text { de } & \text { cada } \\
\text { fragmento } & i j \\
\text { baseado na } & \text { borda } \\
\text { especificada. } & \end{array}$ & $\begin{array}{l}\text { Área núcleo de cada } \\
\text { fragmento (ha). }\end{array}$ \\
\hline $\begin{array}{l}\text { Distância } \\
\text { Euclidiana } \\
\text { Média ao } \\
\text { fragmento } \\
\text { vizinho mais } \\
\text { próximo }\end{array}$ & ENN_MN & ENN_MN $=\frac{\sum_{J=1}^{n} h_{i j}}{n_{i}}$ & $\begin{array}{l}\boldsymbol{h}_{i j}=\text { Distância de } \\
\text { cada fragmento } i j \\
\text { ao seu vizinho mais } \\
\text { próximo. } \\
\boldsymbol{n}_{\bar{i}}=\text { Número de } \\
\text { fragmentos } i .\end{array}$ & $\begin{array}{c}\text { Média das distâncias } \\
\text { euclidianas em metros entre } \\
\text { pontos de borda } \\
\text { de fragmentos vizinhos mais } \\
\text { próximos da mesma classe } \\
\text { de } \\
\text { cobertura }(\mathrm{m}) \text {. }\end{array}$ \\
\hline
\end{tabular}

Quadro 1: Índices de paisagem

\section{MATERIAIS E MÉTODOS}

Os materiais utilizados podem ser subdividos em: dados cartográficos, softwares e material de campo.

Os dados cartográficos são provenientes de fontes distintas. As imagens do satélite Landsat8, sensor TM, cena da órbita ponto 219/074 e 220/074 do ano de 2013 foram obtidas no site do Serviço Geológico dos Estados Unidos (USGS United States Geological Survey). As imagens do radar SRTM (Shuttler Radar Topography Mission), cartas SF-23-V-B, SF-23-V-A, SE-23-Y-D, SE-23-Y-C, do ano 2005 foram disponibilizadas pela Empresa Brasileira de Pesquisa e Agropecuária (EMBRAPA). A fonte do limite municipal é o Instituto Brasileiro de Geografia e Estatística (IBGE); do limite do Parque Nacional da Serra da Canastra é o Ministério do Meio Ambiente (MMA); do limite da zona de amortecimento é o Instituto Brasileiro de Meio Ambiente e Recursos Renováveis (IBAMA). Além dessas, foram utilizadas coordenadas levantadas em trabalho de campo realizado em setembro de 2013.

Os softwares utilizados foram: Envi 4.5 para tratamento das imagens de satélite, Envi EX para o mapeamento da cobertura vegetal e uso do solo, Fragstats 


\section{ANÁLISE DA FRAGMENTAÇÃO DA PAISAGEM DO PARQUE NACIONAL DA SERRA DA \\ CANASTRA E DE SUA ZONA DE AMORTECIMENTO - MG}

para cálculo das métricas de paisagem, ArcGIS 10.1 para álgebra de mapas, elaboração dos mapas temáticos e pós classificação do mapeamento da cobertura vegetal e uso do solo e o GPS TrackMaker Pro para o processamento dos dados de campo.

Por fim, como material de campo foi utilizado o receptor GPS Garmim62 e a Câmera Fotográfica Power Shot SX50 HS.

Os procedimentos metodológicos dividiram-se em três etapas: tratamento e processamento dos dados, mapeamento da cobertura vegetal e do uso do solo e mapeamento da fragmentação da paisagem.

\subsection{Tratamento e processamento dos dados}

Em função de discrepâncias os dados cartográficos foram convertidos para a mesma projeção e datum (UTM-23S/SIRGAS 2000). Para as imagens de satélite foi realizado o realce das bandas a partir do método de ajuste linear de contraste buscando melhorar a qualidade visual e facilitar a interpretação. Na fase seguinte, composição das bandas, visando potencializar as informações e, consequentemente, a capacidade de distinção de alvos durante a classificação foram utilizadas 6 bandas, a saber 2, 3, 4, 5, 6 e 7, todas com resolução espacial de 30 metros. As imagens resultantes da composição foram recortadas de acordo com a área de estudo para facilitar elaboração do mosaico. O mosaico foi realizado pelo método de georreferenciamento com balanceamento automático de cores, de forma a minimizar as diferenças na visualização das imagens utilizadas. Já as imagens do radar SRTM foram mosaicadas utilizando o mesmo método descrito para as imagens de satélite e, posteriormente, recortadas de acordo com o limite da área de trabalho.

\subsection{Mapeamento da cobertura vegetal e uso do solo}

Para o mapeamento da Cobertura Vegetal e Uso do Solo foram utilizadas as imagens pré-processadas na etapa anterior. Elas foram classificadas pelo método não supervisionado utilizando o algoritmo ISODATA com o objetivo de investigar os 


\section{ANÁLISE DA FRAGMENTAÇÃO DA PAISAGEM DO PARQUE NACIONAL DA SERRA DA CANASTRA E DE SUA ZONA DE AMORTECIMENTO - MG}

padrões espectrais existentes para a área de estudo. Por meio desse procedimento foi possível iniciar a identificação das classes que seriam mapeadas de acordo com a resolução espacial da imagem utilizada (30 metros). Para a definição dessas classes foi realizado levantamento bibliográfico e trabalho de campo que possibilitaram a identificação de dez classes que abrangem diferentes usos do solo e cobertura vegetal da área, conforme descrito no Quadro 2 apresentado a seguir.

\begin{tabular}{|c|c|}
\hline Classe & Descrição \\
\hline Formações Florestais & $\begin{array}{l}\text { Vegetação de porte arbóreo-arbustivo: Floresta estacional semidecidual, } \\
\text { savana arborizada, matas de galeria e formações secundárias, como as } \\
\text { capoeiras. }\end{array}$ \\
\hline Formações Campestres & $\begin{array}{l}\text { Vegetação de porte gramíneo-arbustiva: Campo Rupestre Quartzitico, } \\
\text { Campo Limpo, Campo Sujo. }\end{array}$ \\
\hline Cultivo & Áreas com culturas temporárias, perenes e eucalipto. \\
\hline Solo Exposto & $\begin{array}{l}\text { Solo exposto, estradas não pavimentadas, processos erosivos, áreas com } \\
\text { colheita recente. }\end{array}$ \\
\hline Pastagem & Áreas com pastagem plantada. \\
\hline Área Alagada & Áreas nas proximidades das represas que ficam parte do ano submersas. \\
\hline Corpos d'água & Lagos e represas naturais ou artificiais e parte de rios representativos. \\
\hline Área Urbana & Áreas de ocupação urbana. \\
\hline Mineração & Áreas com atividade minerária. \\
\hline Nuvem & Sem informação. A informação foi sobreposta por nuvens. \\
\hline
\end{tabular}

Quadro 2: Descrição das Classes de Cobertura Vegetal e Uso do Solo

Após a definição das classes foi realizada classificação baseada em objeto. Nesse método a segmentação é o passo preliminar e consiste na divisão da imagem em objetos homogêneos e contíguos, de acordo com a heterogeneidade da imagem (forma, textura e cor) e com o limiar de escala definido (tamanho dos objetos). Após alguns testes foi escolhido, para esse trabalho, o nível de escala 60 , sendo que esse varia entre o nível mais grosseiro (100) ao mais detalhado (1) e para o parâmetro de união dos segmentos em subgrupos o valor de 70 .

A classificação final foi realizada no modo supervisionado, com a indicação de no mínimo 20 segmentos para cada uma das classes pré-determinadas, sendo 


\section{ANÁLISE DA FRAGMENTAÇÃO DA PAISAGEM DO PARQUE NACIONAL DA SERRA DA CANASTRA E DE SUA ZONA DE AMORTECIMENTO - MG}

esses utilizados como amostras. Aplicou-se o algoritmo K-Nearest Neighbor que calcula a distância euclidiana entre cada objeto da imagem segmentada e todos os objetos de treinamento definidos para avaliar o grau de pertencimento do segmento em cada classe.

A pós-classificação, realizada no software ArcGIS 10.1, consistiu de conversão da imagem classificada em vetor, validação da classificação por meio de sobreposição com a imagem de satélite, com os pontos de campo e com as imagens disponibilizadas pelo Google Earth e edição vetorial dos polígonos classificados de forma incorreta para sua correção. O mapa de Cobertura Vegetal e Uso do Solo é apresentado a seguir na figura 2.

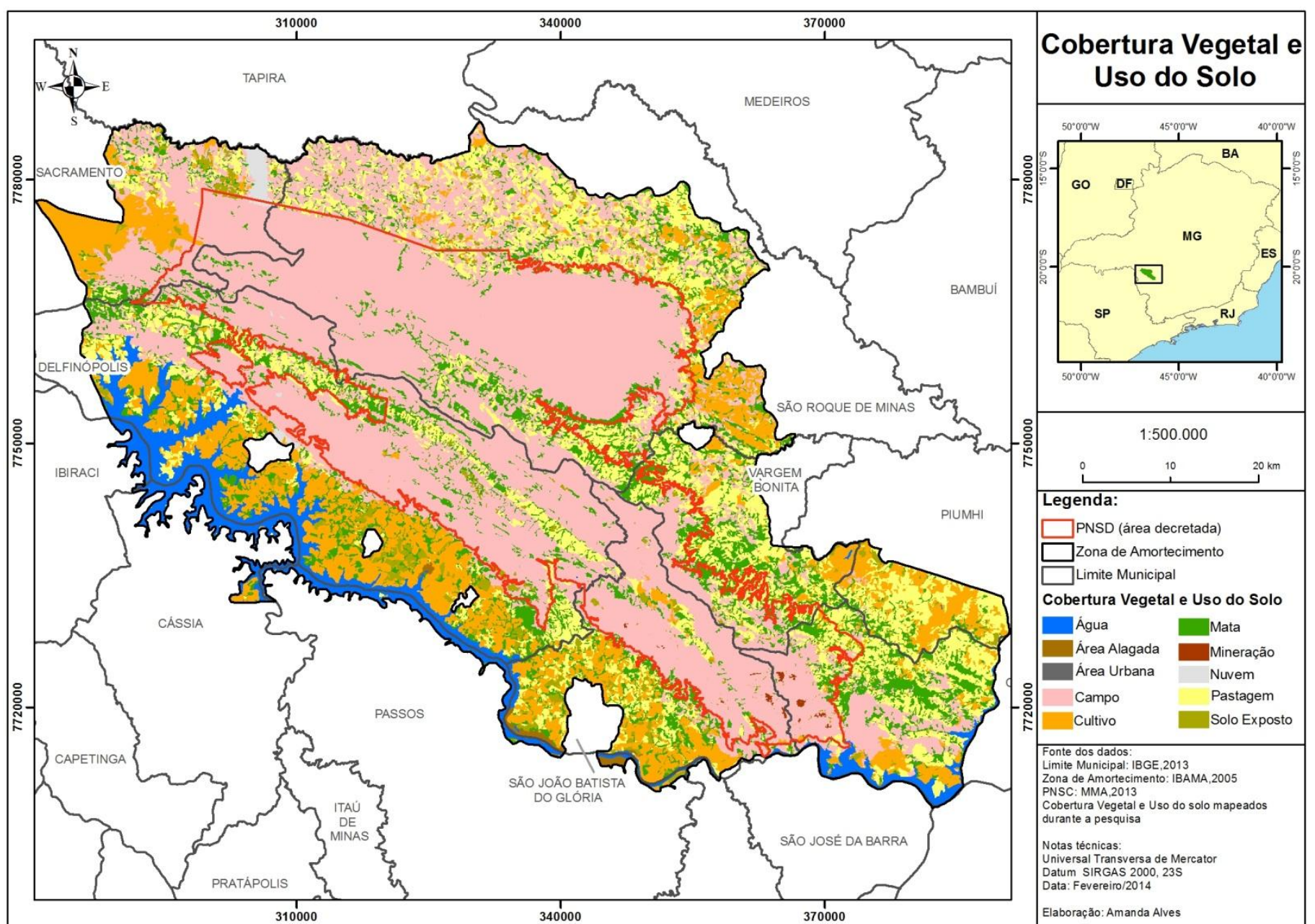

Figura 2: Mapa de Cobertura Vegetal e Uso do Solo 


\section{ANÁLISE DA FRAGMENTAÇÃO DA PAISAGEM DO PARQUE NACIONAL DA SERRA DA \\ CANASTRA E DE SUA ZONA DE AMORTECIMENTO - MG}

\subsection{Mapeamento da fragmentação da paisagem}

Para esse mapeamento foram calculadas métricas ao nível de fragmentos para as Formações Florestais e Formações Campestres constantes no mapa de Cobertura Vegetal e Uso do Solo elaborado. As métricas selecionadas foram: análise de área (AREA), análise de vizinhança (ENN_MN) e análise da área núcleo (CORE). Para o cálculo dessa última optou-se por utilizar uma largura de borda restritiva no valor de $50 \mathrm{~m}$, para o caso do bioma cerrado, uma vez que essa análise proposta não considerava previamente nenhuma espécie alvo ou processo específico.

Os valores obtidos com o cálculo das métricas foram relacionados aos fragmentos por meio do procedimento de união de tabelas (join). As métricas de área e área núcleo foram agrupadas segundo o tamanho nas seguintes classes: menor que 1,1 a 10,10 a 50,50 a 100,100 a 500,500 a 10.000 e maior que 100.000 (valores em hectares). Já a métrica de vizinhança foi subdivida em 7 classes utilizando o método de classificação por quebra natural (Natural Breaks). Os mapas a seguir apresentam a espacialização das métricas calculadas (Figuras 3, $4 \mathrm{e}$ 5).

Como cada uma dessas métricas tem significado ecológico e seus resultados estão relacionados com o nível de fragmentação da paisagem e seus principais efeitos, foi realizada uma reclassificação dos valores das métricas categorizadas para obtenção do mapa síntese de fragmentação da cobertura vegetal.

A reclassificação foi realizada inserindo valores de 1 a 7 para cada categoria das métricas calculadas. Os valores maiores estão relacionados com condições que propiciam um alto grau de fragmentação, por conseguinte os valores menores relacionam-se com as condições contrárias a essas. Na Tabela 1, apresentada a seguir, podem ser observados os valores definidos para cada categoria das métricas calculadas. 


\section{ANÁLISE DA FRAGMENTAC̄ÃO DA PAISAGEM DO PARQUE NACIONAL DA SERRA DA CANASTRA E DE SUA ZONA DE AMORTECIMENTO - MG}

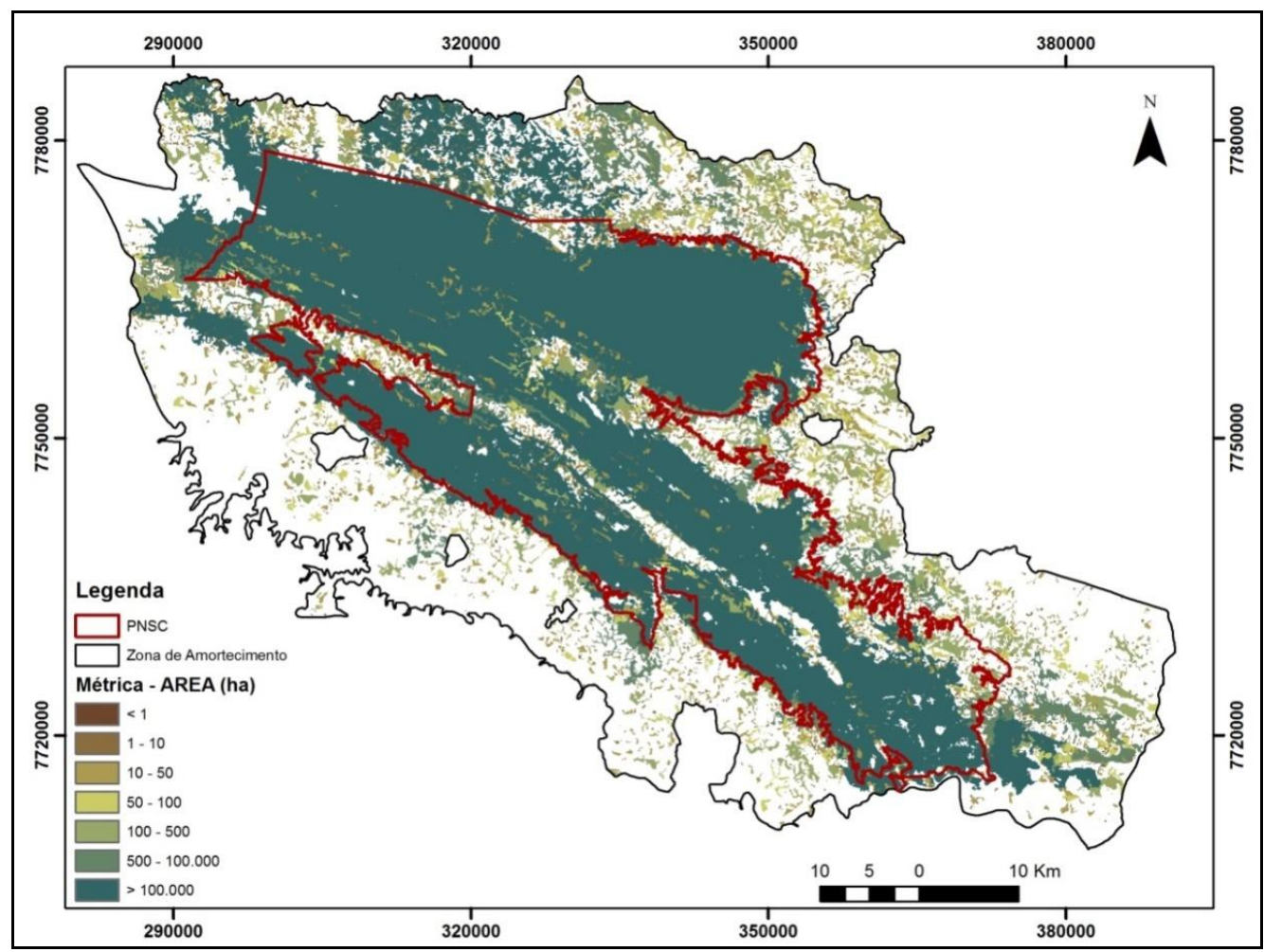

Figura 3: Mapa de Tamanho dos Fragmentos

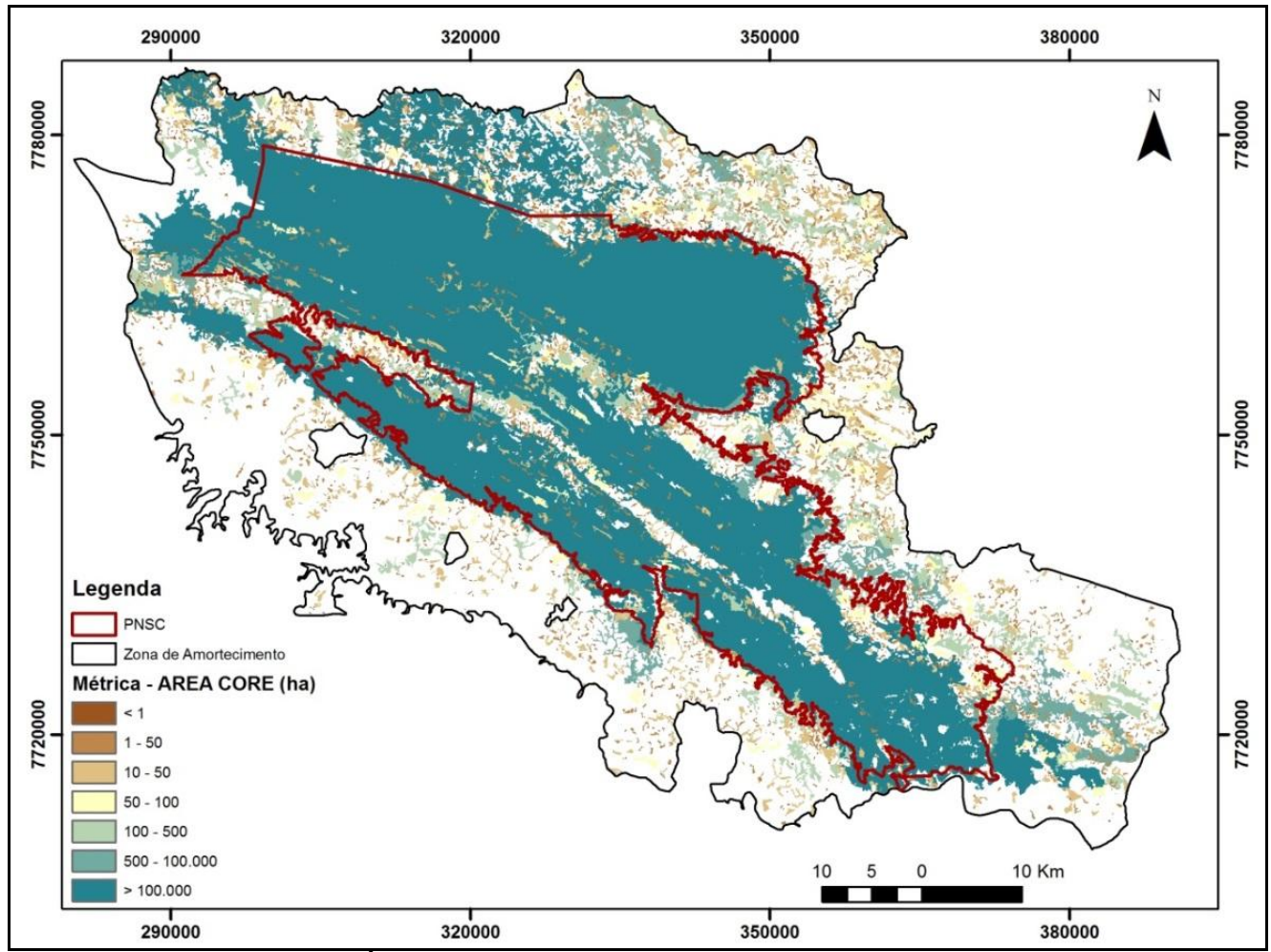

Figura 4: Mapa de Tamanho de Área Núcleo 


\section{ANÁLISE DA FRAGMENTAÇ̃̃O DA PAISAGEM DO PARQUE NACIONAL DA SERRA DA CANASTRA E DE SUA ZONA DE AMORTECIMENTO - MG}

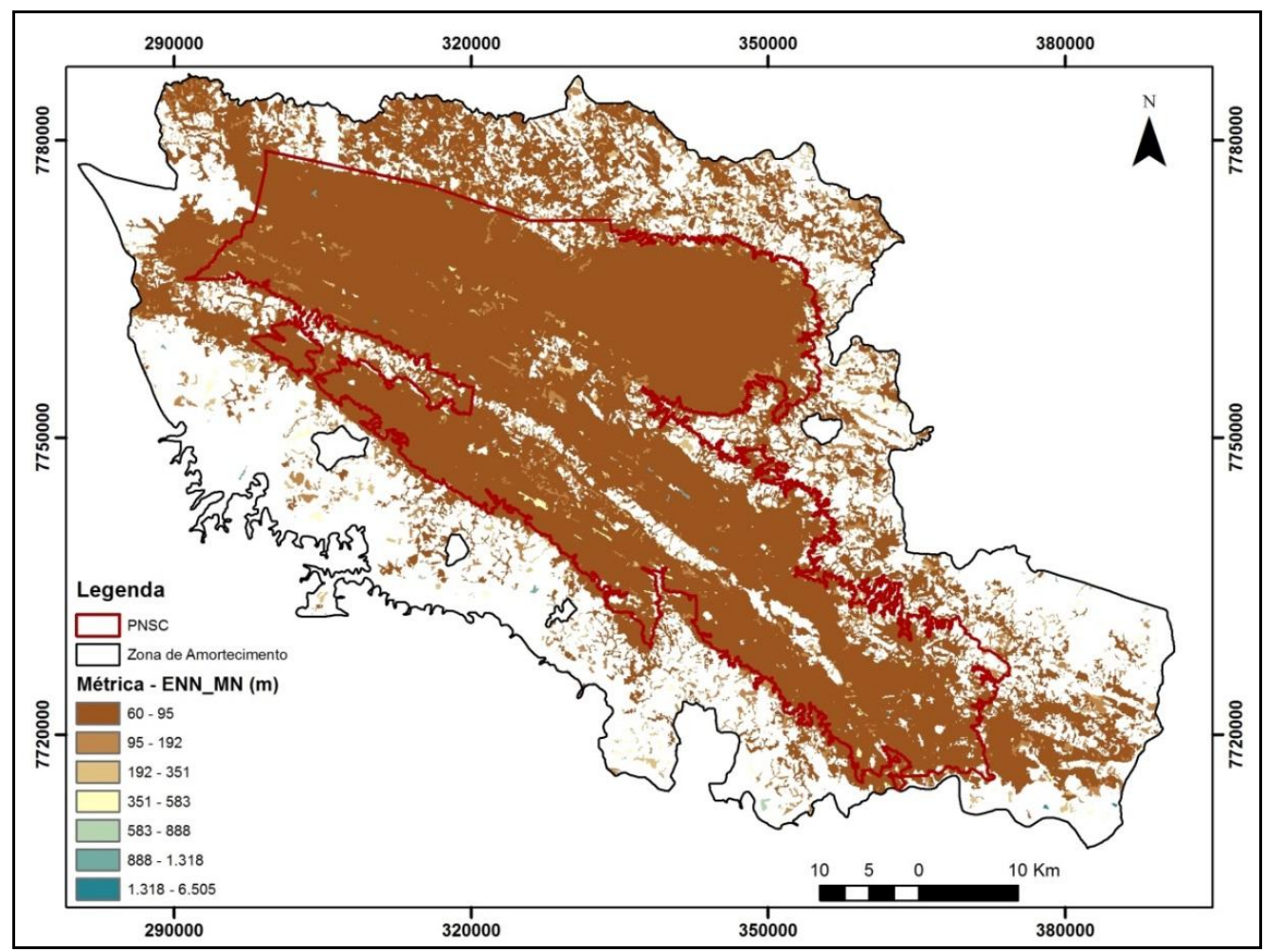

Figura 5: Mapa de Distância dos Fragmentos

Os mapas com as métricas reclassificadas foram submetidos ao processo de álgebra de mapas por meio da equação soma. Os valores resultantes desse processo de somatória pixel a pixel foram classificados por método de quebra natural em três faixas de grau de fragmentação alto, médio e baixo gerando o Mapa Síntese de Grau de Fragmentação da Cobertura Vegetal da área de estudo. 


\section{ANÁLISE DA FRAGMENTAÇ̃̃O DA PAISAGEM DO PARQUE NACIONAL DA SERRA DA \\ CANASTRA E DE SUA ZONA DE AMORTECIMENTO - MG}

Tabela 1: Reclassificação das métricas de paisagem

\begin{tabular}{clc}
\hline Métrica & \multicolumn{1}{c}{ Categoria } & Reclassificação \\
\hline & $<1$ & 7 \\
& $1-10$ & 6 \\
Área (ha) & $10-50$ & 5 \\
& $50-100$ & 4 \\
& $100-500$ & 3 \\
& $500-10.000$ & 2 \\
& $>10.000$ & 1 \\
\hline & $<1$ & 7 \\
Área núcleo & $10-50$ & 6 \\
(ha) & $50-100$ & 5 \\
& $100-500$ & 4 \\
& $500-10.000$ & 3 \\
& $>10.000$ & 2 \\
Vizinhança & $190-95$ & 1 \\
(m) & $352-583$ & 1 \\
& $584-888$ & 2 \\
& $889-1.318$ & 3 \\
& $1.319-6.505$ & 4 \\
& & 5 \\
\hline
\end{tabular}

\section{RESULTADOS E DISCUSSÃO}

A área do Parque Nacional da Serra da Canastra e sua Zona de Amortecimento somam aproximadamente 466.747 ha e é composta pelas seguintes classes de cobertura vegetal e uso do solo: formações campestres, formações florestais, cultivo, pastagem, solo exposto, área alagada, corpos d'água, mineração e nuvem (falta de informação na imagem de satélite). Essas tipologias ocupam porções distintas na área de estudo e apresentam padrões espaciais que revelam a configuração dessa paisagem.

A cobertura vegetal (formações campestres e formações florestais) corresponde a $60,92 \%$ (284,349 ha) do total sendo a maior parte representada por formações campestres. O cultivo e a pastagem, que são a principal forma de uso da área de estudo, ocupam $30,43 \%$ e as outras classes somadas correspondem $8,65 \%$ 


\section{ANÁLISE DA FRAGMENTAÇÃO DA PAISAGEM DO PARQUE NACIONAL DA SERRA DA \\ CANASTRA E DE SUA ZONA DE AMORTECIMENTO - MG}

da área total. Para análise da fragmentação as classes de cobertura vegetal foram utilizadas como referência por serem ambientes naturais e, consequentemente, os mais impactados com os efeitos da fragmentação. A partir do cálculo das métricas e do significado ecológico de seus resultados foi elaborado o Mapa de Grau de Fragmentação do Parque Nacional da Serra da Canastra e sua Zona de Amortecimento (Figura 6).

De acordo com os índices ou métricas calculados os fragmentos maiores que 10 ha correspondem a 270.756 ha do total ocupado por remanescentes de cobertura vegetal e estão concentrados em apenas $25 \%$ dos fragmentos, sendo que a mancha mais representativa corresponde a 194.587 ha da área total. Devido à alta porcentagem de fragmentos menores que 10 ha (75\%) e à sua distribuição espacial, constatou-se uma heterogeneidade significativa nessa paisagem causada, principalmente, por fatores abióticos e perturbações naturais e antrópicas.

Os graus de fragmentação identificados estão associados diretamente com o significado ecológico de cada métrica utilizada na análise. Por meio do mapa apresentado é possível observar que as manchas com baixo grau de fragmentação ocupam áreas maiores e estão espacialmente concentradas, ou seja, apresentam menor distância entre vizinhos da mesma classe e, consequentemente, maior conectividade. Já os fragmentos com alto e médio grau de fragmentação correspondem a áreas menores, não apresentam padrão de distribuição espacial na área de estudo e tem menor área utilizável para espécies sensíveis ao efeito de borda.

Dentre as manchas de cobertura vegetal mapeadas há um expressivo fragmento localizado, principalmente, nas serras e chapadas que, mesmo tendo um formato bastante irregular, apresenta baixo grau de fragmentação devido a sua significância em termos de área e área núcleo e ao potencial de conectividade apresentado pela proximidade com outros fragmentos. 


\section{ANÁLISE DA FRAGMENTAÇ̃̃O DA PAISAGEM DO PARQUE NACIONAL DA SERRA DA CANASTRA E DE SUA ZONA DE AMORTECIMENTO - MG}

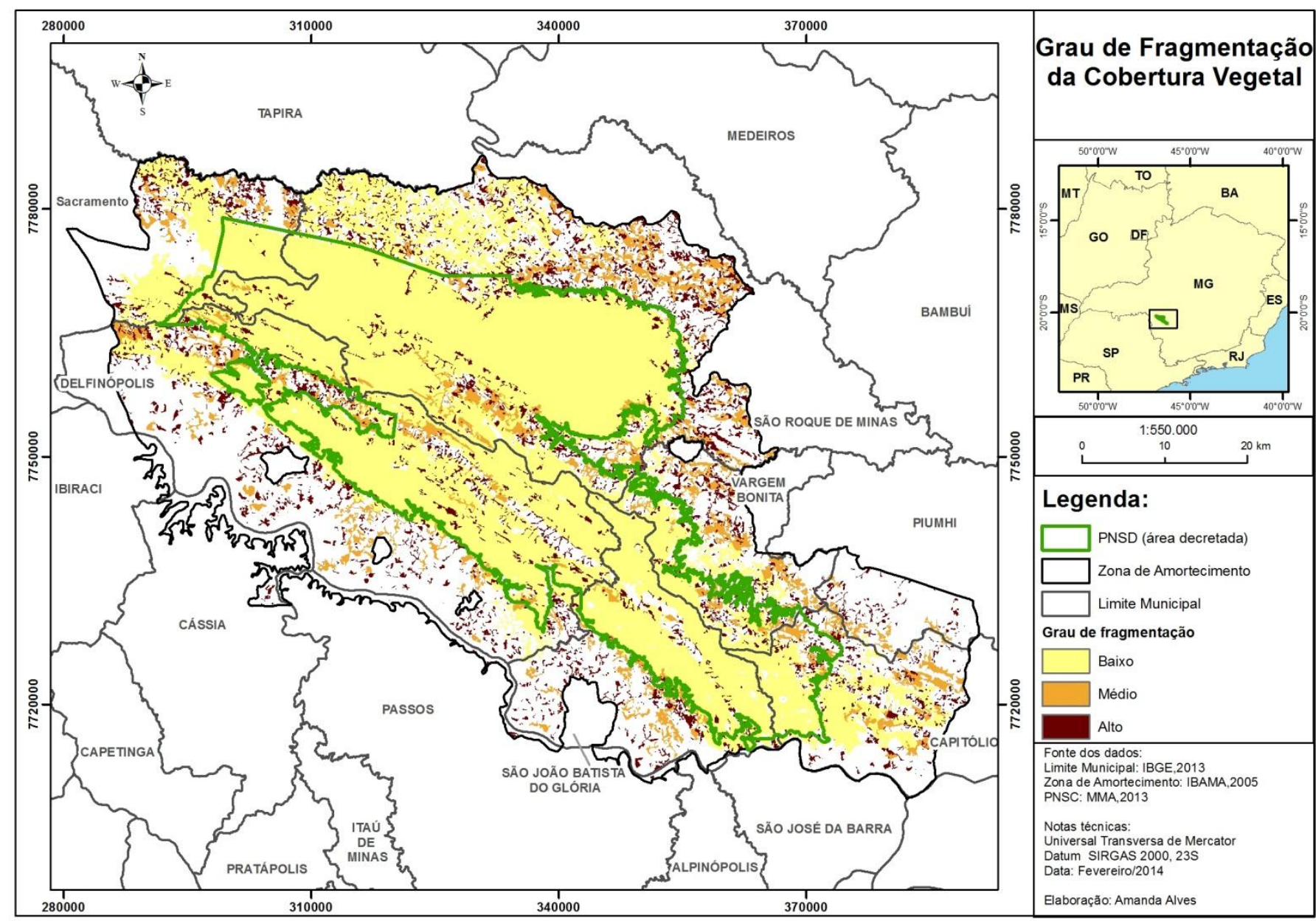

Figura 6: Mapa de Grau de Fragmentação

As formações florestais que, na maioria das vezes, são representadas por uma vegetação ciliar degradada, ocupam pequenas áreas, distantes de outros fragmentos, ou seja, com pouca conectividade. Isso tem relação com o alto grau de fragmentação apresentado, sendo esse identificado, principalmente, nas áreas com altitudes menores que as encontradas nas serras e chapadas.

Dessa forma, percebe-se com clareza que o grau de fragmentação está diretamente relacionado com o relevo, sendo inversamente proporcional a altitude. Nos locais onde há maiores altitudes há menor fragmentação do que nas áreas do entorno, onde as altitudes são menores. Esta constatação também pode ser ratificada pela observação da redução da cobertura vegetal e pelo grau de 


\section{ANÁLISE DA FRAGMENTAÇÃO DA PAISAGEM DO PARQUE NACIONAL DA SERRA DA \\ CANASTRA E DE SUA ZONA DE AMORTECIMENTO - MG}

fragmentação identificado nos vales entre as chapadas e, principalmente, nas porções leste e sul do PNSC.

É importante ressaltar que, apesar da existência de alta proporção de áreas com baixo grau de fragmentação, elas se mantêm, principalmente, por causa das altas altitudes delimitadas por encostas escarpadas. Assim, faz-se necessário, ações para recuperar, por meio do reestabelecimento da conectividade e contiguidade, as áreas com baixo e médio grau de fragmentação. Além disso, as áreas que não apresentam cobertura vegetal devem ser avaliadas sob os aspectos de manejo e restauração de forma reestabelecer os processos ecológicos dessa paisagem.

\section{CONCLUSÕES}

As Unidades de Conservação brasileiras ainda tem um longo caminho a trilhar para cumprirem mais adequadamente os seus objetivos básicos. No Parque Nacional da Serra da Canastra há uma intensa pressão antrópica causada pela indefinição dos limites do parque, presença de rodovias, estradas, áreas de mineração, pastagem e agricultura. O planejamento e a gestão dessa UC são de grande importância para a manutenção de sua viabilidade ecológica e devem considerar ações que envolvam a restauração da paisagem do seu entorno possibilitando o fluxo genético entre espécies e reduzindo a fragmentação.

A realização desse trabalho foi baseada em uma abordagem de cunho geográfico/ecológico, por meio da perspectiva integradora do estudo da paisagem e do uso de métodos de análise espacial. Esses possibilitaram a realização de análises da estrutura da paisagem revelando tendências gerais da influência das atividades humanas sobre o mosaico da paisagem.

O cálculo das métricas permitiu obter valores descritivos da estrutura e do padrão da paisagem revelando importantes aspectos de sua heterogeneidade. Foram mapeados os graus de fragmentação propiciando a compreensão da disposição dos fragmentos e das suas diferentes situações ambientais. Percebeu-se que o grau de fragmentação está mais relacionado com as formações 


\section{ANÁLISE DA FRAGMENTAÇÃO DA PAISAGEM DO PARQUE NACIONAL DA SERRA DA CANASTRA E DE SUA ZONA DE AMORTECIMENTO - MG}

geomorfológicas do que com a existência da Unidade de Conservação e, por conseguinte, à polêmica de seus limites.

O fragmento remanescente mais significativo, localizado nas chapadas e nos morros alongados da porção norte, está praticamente isolado, ou seja, não há outros fragmentos com condições ambientais semelhantes em suas proximidades. Sendo assim, vale ressaltar a importância da restauração dos fragmentos menores, já que esses cumprem funções relevantes ao longo da paisagem, funcionando como trampolins ecológicos (stepping stones), promovendo um aumento no nível de heterogeneidade da matriz e atuando como refúgio de espécies que requerem ambientes particulares que só correm nessas áreas.

\section{REFERÊNCIAS}

CASIMIRO, P. C. Estrutura, composição e configuração da Paisagem, conceitos e princípios para a sua quantificação no âmbito da Ecologia da Paisagem. Revista Portuguesa de Estudos Regionais, Revista da APDR, Coimbra, ํㅡㄹ 20, p. 75-97, 1ํㅡㄴ quadrimestre 2009.

CASTRO JUNIOR, E; COUTINHO, B.H; FREITAS, L.E. Gestão da Biodiversidade e Áreas Protegidas. . In GUERRA, A.J.T; COELHO, C. N.(Org.). Unidades de Conservação: Abordagens e Características Geográficas. Rio de Janeiro: Bertrand Brasil LTDA, p. 25-65. 2009.

DIOS, C. B; MARÇAL, M. S. Legislação Ambiental e a Gestão de Unidades de Conservação: O Caso do Parque Nacional da Restinga de Jurubatiba - RJ. In GUERRA, A.J.T; COELHO, C. N.(Org.). Unidades de Conservação: Abordagens e Características Geográficas. Rio de Janeiro: Bertrand Brasil LTDA, p. 173-199. 2009.

DRAMSTAD, W.E.; OLSON, J.D.; FORMAN, R.T.T. Landscape Ecology Principles in Landscape Architecture and Land-Use Planning. Island Press, 80 p. 1996.

FORMAN, R.T; GODRON, M. Landscape Ecology. New York: Wiley, 1986. 619p.

LANG, S.; BLASCHKE, T. Análise da paisagem com SIG. 2006. São Paulo: Oficina de Textos. 424p. 


\section{ANÁLISE DA FRAGMENTAÇÃO DA PAISAGEM DO PARQUE NACIONAL DA SERRA DA \\ CANASTRA E DE SUA ZONA DE AMORTECIMENTO - MG}

METZGER, J. P. O que é ecologia de paisagens?. Biota Neotropica (ED. Portuguesa), Campinas, v.1, n.1/2, p.1-9, 2001.

METZGER, J. P. Estrutura da paisagem: O uso adequado de métricas. In: CULLEN, L. Jr.; RUDRAN, R.; VALLADARES-PADUA, C. (Org). $2^{\circ} e d$. Métodos de Estudos em Biologia da Conservação e Manejo da Vida Silvestre. Curitiba: Ed. Universidade Federal do Paraná, 2009, p. 423-453.

MITTERMEIER, A.R. et al. Uma breve história da conservação da biodiversidade no Brasil. MEGADIVERSIDADE, v.1, n.1, p.14-21, 2005.

MOURA, A. C. M.; Reflexões Metodológicas para estudos ambientais baseados em Análise de Multicritérios. In: Simpósio Brasileiro de Sensoriamento Remoto, 2007, Florianópolis. Anais XIII Simpósio Brasileiro de Sensoriamento Remoto SBSR. São Paulo: INPE, p.2899-2906. 2007.

MURCIA, C. Edges effects in fragmented forests: implications for conservation. Elsevier Science. v. 3, n. 10, p. 58-62, 1995.

RAMBALDI, D. M.; OLIVEIRA, D. A.S. (orgs.). Fragmentação de ecossistemas: causas, efeitos sobre a biodiversidade e recomendações de políticas públicas. Brasília: MMA/SBF, 2003.

SOARES-FILHO, B. S. Análise de Paisagem: Fragmentação e Mudanças. Apostila. Departamento de Cartografia, Centro de Sensoriamento Remoto - Instituto de Geociências - UFMG, 1998.

TURNER, M. G. Landscape ecology: the effect of pattern on process. Annual Review of Ecology and Systematic, v. 20, p.171-197, 1989.

UEZU, A. C. Jr. Da fragmentação florestal à restauração da paisagem: aliando conhecimento científico e oportunidades legais para a conservação. In: PAESE, A.; UEZU, A.; LORINI, M.L.; CUNHA, A. (Org.). Conservação da Biodiversidade com SIG. São Paulo: Oficina de Textos, p.13-22. 2012. 